\title{
Conformational templating of a-synuclein aggregates in neuronal-glial cultures
}

\author{
Amanda N Sacino, Michael A Thomas, Carolina Ceballos-Diaz, Pedro E Cruz, Awilda M Rosario, Jada Lewis, \\ Benoit I Giasson * and Todd E Golde*
}

\begin{abstract}
Background: Genetic studies have established a causative role for a-synuclein (aS) in Parkinson's disease (PD), and the presence of aS aggregates in the form of Lewy body (LB) and Lewy neurite $(L N)$ protein inclusions are defining pathological features of PD. Recent data has established that extracellular aS aggregates can induce intracellular aS pathologies supporting the hypothesis that aS pathology can spread via a "prion-like" self-templating mechanism.

Results: Here we investigated the potential for conformational templating of aS intracellular aggregates by seeding using recombinant wild-type and PD-linked mutant (A53T and E46K) aS in primary mixed neuronal-glial cultures. We find that wild-type and A53T aS fibrils predominantly seed flame-like inclusions in both neurons and astrocytes of mixed primary cultures; whereas the structurally distinct E46K fibrils seed punctate, rounded inclusions. Notably, these differences in seeded inclusion formation in these cultures reflect differences in inclusion pathology seen in transgenic mice expressing the A53T or E46K aS mutants. We further show that the inclusion morphology is dictated primarily by the seed applied rather than the form of aS expressed. We also provide initial evidence that aS inclusion pathology can be passaged in primary astrocyte cultures.
\end{abstract}

Conclusion: These studies establish for the first time that aS aggregation in cultured cells can occur by a morphological self-templating mechanism.

Keywords: a-Synuclein, Parkinson's disease, Self-templating, Amyloid, Prion

\section{Background}

Parkinson's disease (PD) is the most common movement neurodegenerative disorder [1]. PD belongs to a spectrum of neurodegenerative diseases, termed $\alpha$ synucleinopathies, unified by the presence of the brain accumulation of neuronal and glial $\alpha$-synuclein $(\alpha S)$ inclusions [2,3]. The physiologic function of $\alpha \mathrm{S}$ is still not completely established; however, $\alpha \mathrm{S}$ gene $(S N C A)$ defects that cause autosomal-dominant PD ( $S N C A$ gene duplication/triplication and missense mutations A30P, E46K, G51D, H50Q, and A53T) have clearly established a causal role for $\alpha \mathrm{S}$ in disease [4-13]. Differences in the clinical profiles and pathology of PD patients and mouse models with either the A53T or E46K mutation have been documented [4,5,14-16]. In vitro biochemical studies on amyloidogenic $\alpha \mathrm{S}$ fibrils derived from A53T and

\footnotetext{
*Correspondence: bgiasson@ufl.edu; tgolde@ufl.edu Department of Neuroscience, McKnight Brain Institute, Center for Translational Research in Neurodegenerative Disease, University of Florida College of Medicine, 1275 Center Drive, Gainesville, FL 32610, USA
}

E46K missense mutations have also shown differences in nucleation and elongation of fibril polymerization, peptide structural order, and ultrastructural morphology [17-21].

Recent postmortem studies in PD patients suggest that the spread of pathology can occur intercellularly [22-26], and the induction of $\alpha \mathrm{S}$ pathology in experimental mouse models using intracerebral injection of recombinant $\alpha \mathrm{S}$ fibrils suggests that amyloidogenic $\alpha \mathrm{S}$ may also spread by a "prion-like" mechanism $[27,28]$. A key characteristic of "prion-like" transmission is permissive templating, in which the amyloidogenic form of the protein interacts with normal endogenous protein, and that interaction induces a conformational change in the endogenous protein to an amyloidogenic $\beta$-pleated sheet structure $[29,30]$. A major difference between "prionlike" transmission and classical prion disease is paucity of inter-organism transmission. For many amyloids this "prion-like" conversion of protein conformation can often have unique structural and morphological 
properties that can be transmitted and this phenomenon has been termed "strain-specific" $[29,30]$.

Taking advantage of previous in vitro observations that wild-type, A53T, and E46K $\alpha \mathrm{S}$ amyloids have distinct structural properties [17-21,31] and that pathological inclusions in $\mathrm{A} 53 \mathrm{~T}$ and $\mathrm{E} 46 \mathrm{~K}$ transgenic mice are also distinct $[14,15]$, we used a novel recombinant adeno-associated virus (rAAV)-mediated $\alpha \mathrm{S}$ primary neuronalglial culture model to test the hypothesis that fibrillar A53T and E46K $\alpha \mathrm{S}$ may seed cellular inclusions with unique morphological properties. We show that neuronal and astrocytic inclusions formed by fibrillar A53T and $\mathrm{E} 46 \mathrm{~K} \alpha \mathrm{S}$ are morphologically consistent with those in transgenic mice and that the seeding fibrils (i.e., A53T versus E46K $\alpha \mathrm{S}$ ) have a dominant effect over the $\alpha \mathrm{S}$ protein expressed. We also find that inclusion pathology induced by exogenous fibrils in one astrocyte culture can be passaged to a second astrocyte culture. This data provides important support for a conformational templating of $\alpha \mathrm{S}$ inclusion pathology.

\section{Results \\ Induction of aS aggregates in primary mixed neuronal- glial cultures}

In previous studies, we and others [32-34] have shown that under experimental conditions that promote the entry of exogenous recombinant $\alpha \mathrm{S}$ fibrils, the formation of robust Lewy body (LB)-like inclusions can be induced in cultured cell lines overexpressing human $\alpha \mathrm{S}$. To determine if we could induce inclusion formation in primary mixed mouse neuronal-glial cultures, we tested whether overexpression of wild-type human $\alpha \mathrm{S}$ mediated by $\mathrm{rAAV} 2 / 1$ vectors and addition of amino-terminally truncated exogenous recombinant wild-type (21-140) $\alpha S$ fibrils was sufficient to induce $\alpha S$ aggregate formation. We assessed $\alpha \mathrm{S}$ aggregate formation using several previously established methods. First, we used antipSer129 $\alpha \mathrm{S}$ antibody immunoreactivity, since $\alpha \mathrm{S}$ inclusions are hyperphosphorylated at Ser129 and this modification is an excellent marker of aggregate formation [32-37]. However, in primary neuronal cultures used here this antibody also recognizes a non- $\alpha \mathrm{S}$ target localized only in MAP2 positive neuronal processes, as it stains these processes in cultures from wild-type and SNCA null mice (Figure 1). Therefore, co-localization of pSer129 and a second $\alpha S$ antibody, SNL-4, were used to track inclusion formation. Notably, the SNL-4 antibody binds the extreme amino terminus of $\alpha \mathrm{S}$. Using seeding with exogenous 21-140 and full-length $\alpha \mathrm{S}$ fibrils, we previously showed that this antibody also stains the intracellular inclusions [32,38] and therefore can be used to distinguish the non-specific neuritic background staining seen with pSer129. In the primary mixed neuronal-glial cultures, $\alpha \mathrm{S}$ predominantly demonstrated a punctate neuronal staining profile reflecting a presynaptic distribution (Figure 1A), as previously demonstrated $[39,40]$. rAAV2/1-mediated overexpression of $\alpha \mathrm{S}$ increased both the presynaptic and nuclear staining intensity for $\alpha S$, but did not affect the neuritic staining of the pSer129 non$\alpha S$ target (Figure 1B). Addition of preformed fibrils alone resulted in pSer129 staining of processes similar to that seen in blank controls, but this staining did not co-localize with SNL-4 (Figure 1C). Addition of exogenous fibrils and overexpression of $\alpha \mathrm{S}$ were both required to induce $\alpha \mathrm{S}$ aggregate formation (Figure 1D). When robust aggregate formation is present, the staining of these aggregates with pSer129 is much more robust then the non- $\alpha \mathrm{S}$ target, therefore the weaker signal of the non- $\alpha S$ target is more difficult to observe when capturing images that are appropriate to visualize pSer129 labeled $\alpha S$ aggregates.

In this system where we overexpressed $\alpha \mathrm{S}$ using rAAV2/ 1 and added extracellular preformed $\alpha \mathrm{S}$ fibrils to induce intracellular aggregate formation, inclusion formation was rapid and efficient. Using rAAV2-1 wild-type $\alpha \mathrm{S}$ and wildtype $\alpha \mathrm{S}$ fibrils, $0.4 \pm 0.1 \%$ and $29.1 \pm 3.8 \%$ of the transduced cells formed aggregates by 1 and 4 days following fibril addition, respectively. However, aggregate formation was accelerated if either E46K or A53T mutant $\alpha \mathrm{S}$ was expressed or used for seeding as demonstrated by the percentage of transduced cells with aggregates at 1 day following the addition of fibrils: rAAV2- 1 wild type- $\alpha$ S/A53T fibrils (1.5 $\pm 0.2 \%)$, rAAV2-1 wild type- $\alpha$ S/E46K fibrils $(2.6$ $\pm 1.2 \%)$, rAAV2-1 A53T $\alpha$ S/A53T fibrils (16.3 $\pm 6.7 \%)$, rAAV2-1 A53T $\alpha$ S/E46K fibrils (7.9 $\pm 2.4 \%)$, rAAV2-1 A53T $\alpha$ S/wild-type fibrils (11.9 $\pm 1.9 \%)$, rAAV2-1 E46K $\alpha$ S/ A53T fibrils $(3.5 \pm 0.6 \%)$, rAAV2-1 E46K $\alpha$ S/E46K fibrils (1.7 $\pm 0.3 \%)$, rAAV2-1 E46K $\alpha$ S/wild type fibrils (3.2 $\pm 0.6 \%)$.

As additional controls to show that seeding with amyloidogenic $\alpha \mathrm{S}$ was required for intracellular aggregate formation, we treated cultures overexpressing $\alpha S$ with $\beta$-synuclein or non-amyloidogenic $\Delta 71-82 \alpha S$ (Figure 2) [33,41]. Treatment with either of these proteins did not result in intracellular aggregate formation, but non-specific pSer129 staining in neuronal processes was still apparent.

To establish that these pSer129 and SNL-4 immunostained aggregates were bonafide inclusions, we conducted biochemical fractionation and Western blot analysis previously used to validate the presence of Triton-insoluble $\alpha \mathrm{S}$ aggregates in culture [32]. As shown in Figure 3A, rAAVmediated $\alpha S$ overexpression in combination with the addition of extracellular $\alpha \mathrm{S}$ fibrils induced the formation of Ser129 hyper phosphorylated Triton-insoluble aggregates.

To validate that extracellular, exogenous aggregates could enter cells and be incorporated into intracellular $\alpha \mathrm{S}$ inclusions, Thioflavin-S pre-labeled recombinant $\alpha \mathrm{S}$ fibrils were added to cultures and shown to be present within intracellular aggregates (Figure 3B). 


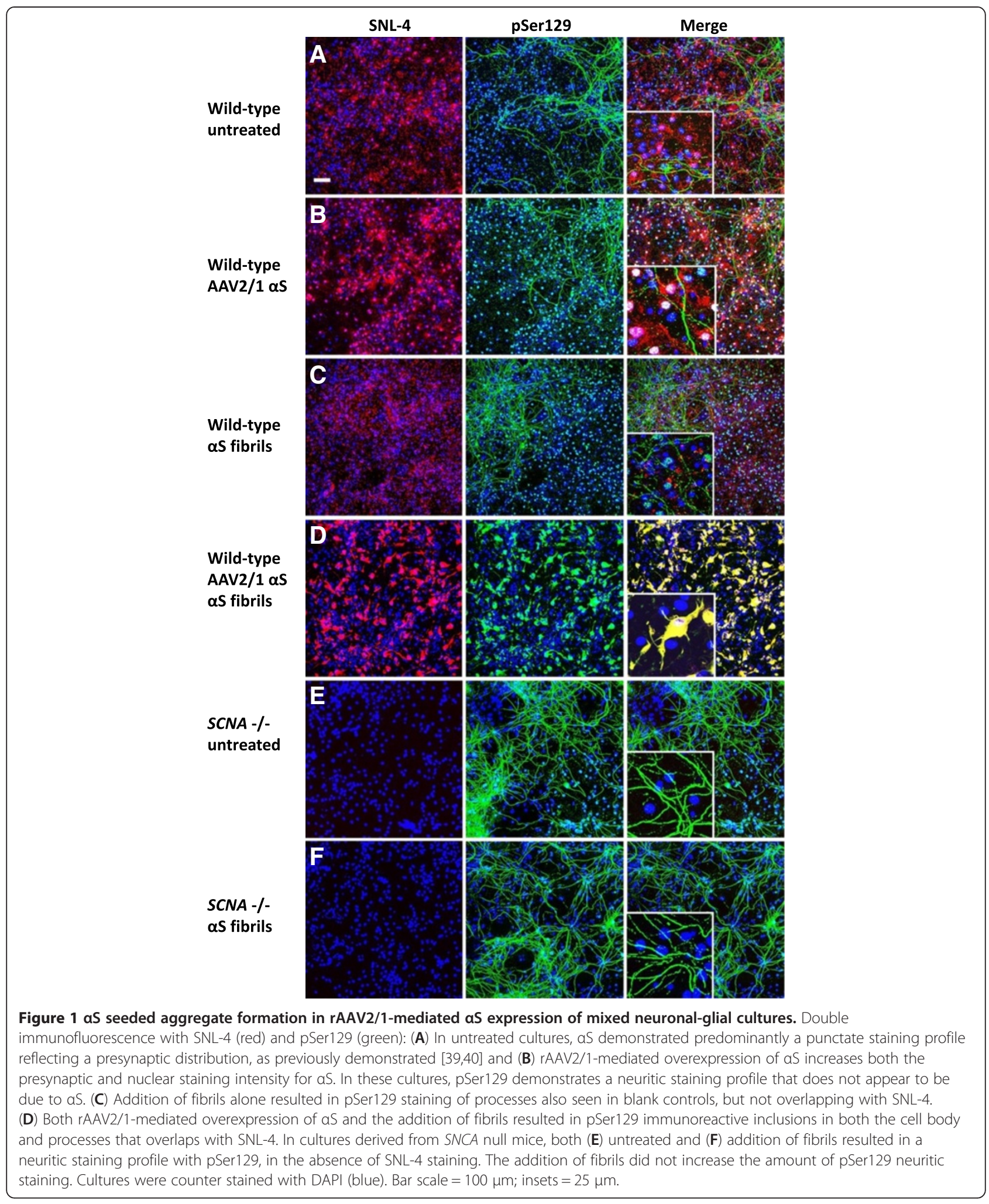

To assess which types of cells were prone to display $\alpha \mathrm{S}$ aggregate formation; we performed double immunofluorescence with the neuronal specific marker MAP2B and the astrocyte specific marker GFAP (Figure 4).
Inclusion formation was readily observed in both cell types. In many experiments 4 days post-seeding, more than $50 \%$ of both SNL-4+ MAP2+ neurons and GFAP+ SNL-4+ astrocytes demonstrated pSer129+ aggregates 


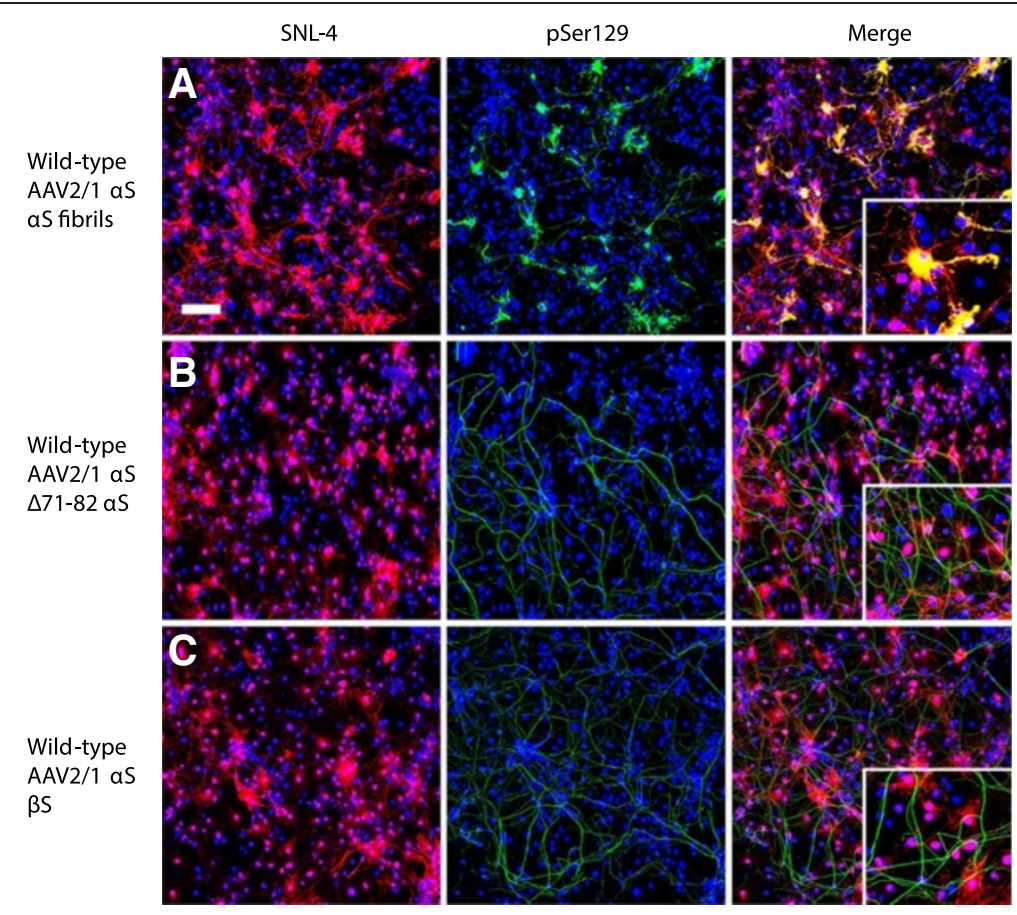

Figure 2 Non-amyloidogenic synuclein proteins do not induce aS inclusion pathology. Double immunofluorescence with SNL-4 (red) and pSer129 (green): Mixed neuronal-glial cultures with rAAV2/1-mediated overexpression of aS were treated with (A) fibrillar aS, (B) $\triangle 71-82$ aS or (C) $\beta$-synuclein. Only treatment with fibrillar aS resulted in Ser129 hyperphosphorylated aS aggregates. Cultures were counter stained with DAPI (blue). Bar scale $=100 \mu \mathrm{m}$; insets $=25 \mu \mathrm{m}$.

using the rAAV2/1 wild-type $\alpha S$ and wild-type fibril combination. By 8 days post-seeding, nearly all cells that were transduced with the rAAV2/1 $\alpha \mathrm{S}$ and were SNL-4+ showed pSer129+ inclusions. As the rAAV2/1 vectors efficiently transduce greater than $50 \%$ of astrocytes and neurons in culture, these studies reveal that this system shows remarkable efficiency of inclusion formation. Although $\alpha \mathrm{S}$ is predominantly found at higher endogenous levels in neurons [39,42-44], by using rAAV driven expression, astrocytes are also as vulnerable to $\alpha \mathrm{S}$ aggregate formation.

$\alpha \mathrm{S}$ aggregates formed in our cellular system are similar to those observed in human brains. The inclusions are partially ubiquitinated and are Thioflavin-S (ThS) positive (Figures 5 and 6). In cultures treated with rAAV2/1 human wild-type $\alpha \mathrm{S}$, the neuritic staining profile seen with pSer129 does not overlap with endogenous ubiquitin (Figure 5A). The overexpression of human wild-type $\alpha \mathrm{S}$ (via rAAV2/1) plus exogenous human $\alpha \mathrm{S}$ fibrils produced pSer129+ $\alpha \mathrm{S}$ aggregates that co-localize with ubiquitin (Figure 5B). Co-localization of ubiquitin staining with pSer129+ $\alpha S$ aggregates is seen both in neurons (Figure 5C) and astrocytes (Figure 5D). Similarly, pSer129+ aggregates show co-localization with ThS (Figure 6A). The ThS staining profile is seen in both neurons (Figure 6B) and astrocytes (Figure 6C). However, it appears that ThS only stains a fraction of the
pSer129 immunoreactive inclusions, suggesting that even within individual cells the structure of the aggregate is not homogenous.

\section{Morphological differences in aS pathology seen in primary mixed neuronal-glial cultures}

Transgenic mouse models for human A53T (line M83) and E46K (line M47) $\alpha \mathrm{S}$ have been developed and characterized $[14,15]$. Both transgenic models express similar levels of human $\alpha \mathrm{S}$ under the control of mouse prion protein promoter and develop similar age-dependent motor phenotypes associated with similar widespread distribution of neuronal $\alpha \mathrm{S}$ inclusions. However, the $\alpha \mathrm{S}$ pathology in the M83 transgenic model predominantly demonstrates a flame-like somatodendritic and neuritic profile; whereas, those seen in the M47 transgenic model have a rounded and compact profile (Figure 7). We therefore studied the effects that the A53T and E46K mutations would have on the morphology of $\alpha \mathrm{S}$ pathology, and whether these differences were due predominantly to the type of protein being overexpressed, the type of fibril seeding pathology, or both. As seen in Figure 8A, wild-type, A53T, and E46K $\alpha$ S fibrils are able to cross-seed $\alpha \mathrm{S}$ pathology. Regardless of the protein being overexpressed, seeding with A53T fibrils overall induced flame-like somatodendritic inclusions that we will refer to as M83-like pathology; whereas, seeding with 


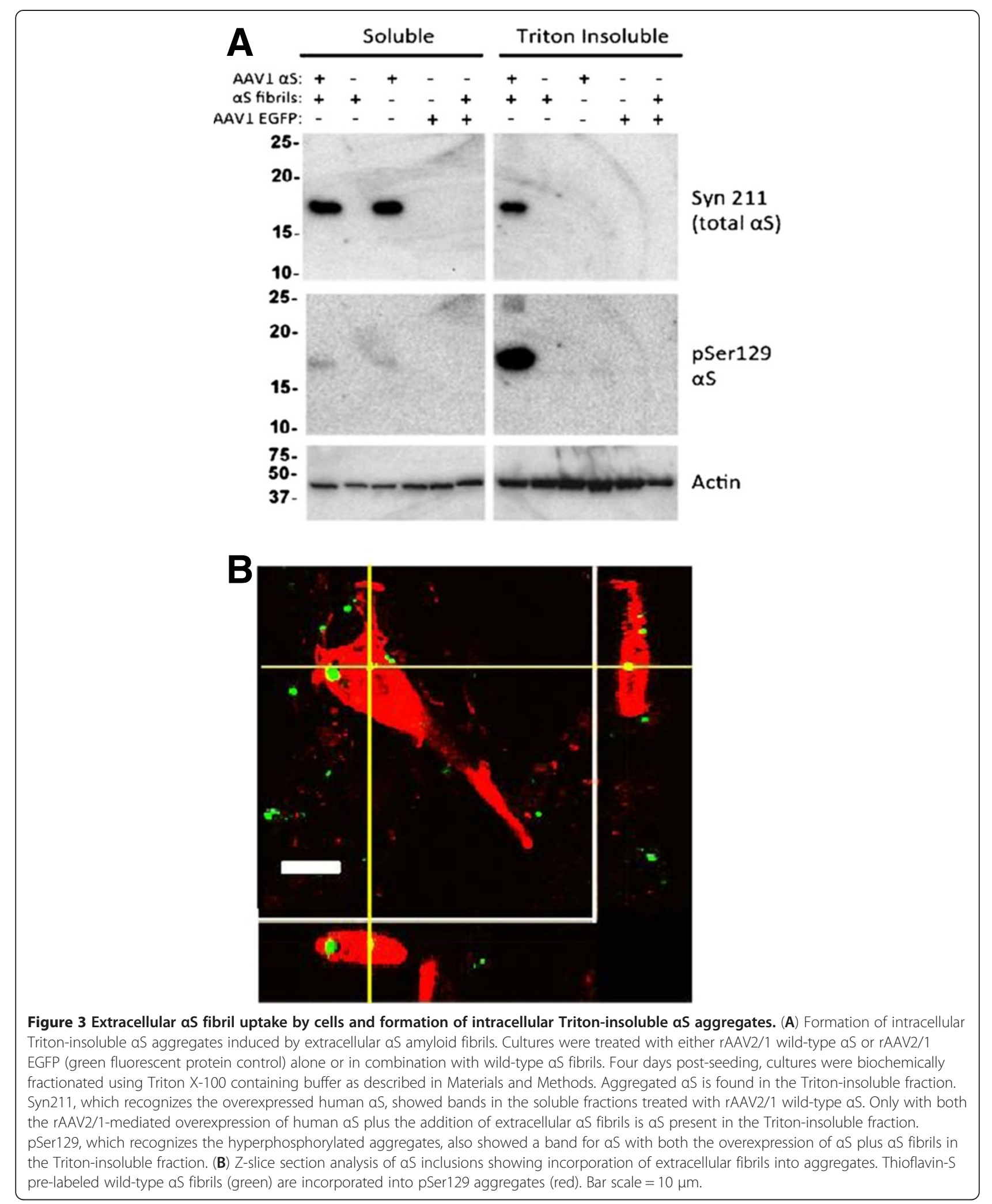



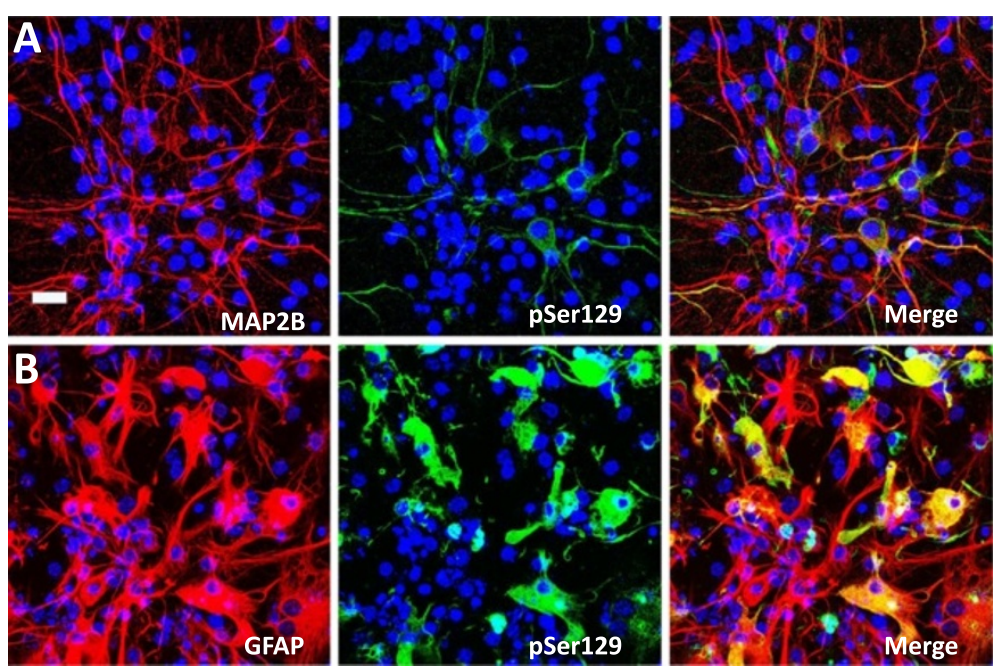

Figure 4 aS aggregate formation in neurons and astrocytes. (A) aS pSer129 positive aggregates (green) induced by treatment with extracellular aS fibrils in cultures with rAAV2/1 human aS expression can occur in neurons as shown by double immunofluorescence with the neuronal marker MAP2B (red). (B) aS pSer129 positive aggregates (green) induced by treatment with extracellular aS fibrils in cultures with rAAV2/1 human aS expression can occur in astrocytes as shown by double immunofluorescence with the astrocyte marker GFAP (red). Cultures were counter stained with DAPI (blue). Bar scale $=25 \mu \mathrm{m}$.

E46K fibrils induced more rounded and compact inclusions that we will refer to as M47-like pathology (Figures 8 and 9). Blinded quantification also showed that the morphology of the inclusions was heavily dependent upon the type of fibril used to seed the culture and that the ratios of M83 to M47-like pathologies were significantly different (all $\mathrm{p}<0.01$ ). As stated above, the rAAV2-1 wild-type $\alpha \mathrm{S}$ / wild-type $\alpha \mathrm{S}$ fibril combination showed slower aggregation kinetics relative to combinations that included a mutant protein, but it resulted mainly in M83-like pathology; however, when wild-type was used to seed A53T or E46K as, the predominant morphology depended upon the protein being expressed, suggesting that wild-type $\alpha \mathrm{S}$ seeds are more mutable or heterogeneous (Figure $8 \mathrm{~B}$ ).

\section{Passaging of aS aggregates via cell lysates in astrocyte cultures}

Our studies showed that $\alpha \mathrm{S}$ aggregate formation can be induced in both neurons and astrocytes (Figure 4). Primary astrocyte cultures have little to no endogenous $\alpha \mathrm{S}$ (SNL-4, Figure 10A) and also lack the background neuritic staining of pSer129 (Figure 10A-D). As with the primary mixed neuronal-glial cultures, the formation of $\alpha S$ aggregates requires both the overexpression of $\alpha S$ (via rAAV2/1) and addition of exogenous fibrillar $\alpha \mathrm{S}$ (Figure 10D). For passaging studies, cultures were treated with $\mathrm{rAAV} 2 / 1$ human wild-type $\alpha \mathrm{S}$ and A53T-derived human $\alpha$ S fibrils.

Cell lysates prepared as described in Material and Methods from the seeded cultures were added to astrocyte cultures overexpressing human wild-type $\alpha \mathrm{S}$ (via
rAAV2/1). The cultures were left to incubate with the lysate for 5 days. Cultures exposed to aggregatecontaining cell lysate from the overexpression of human wild-type $\alpha \mathrm{S}$ and seeding with A53T-derived human fibrils, showed passaging of pSer129 positive aggregates in $2.9 \pm 0.7 \%$ of transduced cells (Figure 11A). In contrast, astrocyte cultures overexpressing human wild-type $\alpha \mathrm{S}$ and seeded with cell lysate from cultures that were treated with either A53T-derived fibrils (Figure 11B), rAAV2/1 human wild-type $\alpha \mathrm{S}$ (Figure 11C), or nothing (Figure 11D), did not show any pSer129 and SNL-4 positive aggregates.

\section{Discussion}

$\alpha S$ inclusions are a hallmark pathology seen in PD and related disorders termed synucleinopathies. Many studies have indicated that aggregated forms of $\alpha \mathrm{S}$ can lead to neuronal demise [45-48]. Therefore it is important to better understand the mechanisms involved in $\alpha \mathrm{S}$ aggregation to develop tools for therapeutic intervention. Previous in vitro studies have shown that soluble $\alpha S$ can efficiently undergo a conformational change into an amyloidogenic, fibrillar form and it is well established that in vitro $\alpha \mathrm{S}$ aggregation into amyloid is a nucleation dependent process and can be greatly induced by the addition of a "seed" or "nucleus" of pre-aggregated $\alpha \mathrm{S}$ $[45-47,49,50]$.

Cellular studies have shown that the entry of a small amount of preformed $\alpha \mathrm{S}$ fibrils into immortalized cell lines using reagents that promote the entry of these seeds across the plasma membrane can very efficiently induce the formation of large intracellular amyloid 


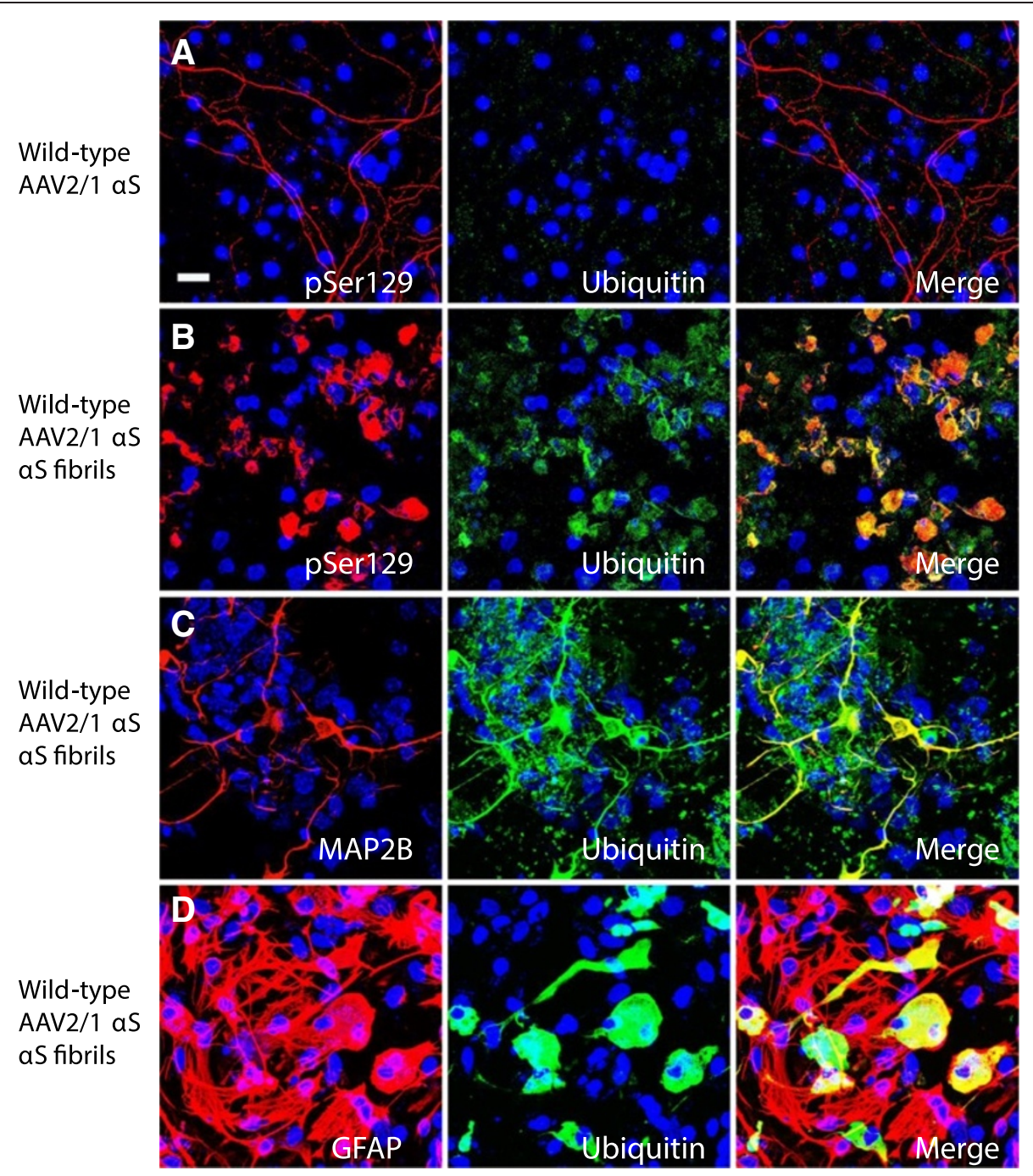

Figure 5 aS inclusions in the mixed neuronal-glial cultures co-localize with ubiquitin. (A) In cultures treated with rAAV2-1 human wild-type aS, pSer129 (red) neuritic background staining does not co-localize with endogenous ubiquitin (green). (B) In cultures treated with rAAV2/1 human wild-type aS and exogenous human wild-type aS fibrils, pSer129 (red) hyperphosphorylated aS inclusions in these cultures are ubiquitinated (green). This ubiquitin staining profile (green) co-localizes with the neuronal marker MAP2B (red, C) and the astrocyte marker GFAP (red, D). Cultures were counter stained with DAPI (blue). Bar scale $=25 \mu \mathrm{m}$.

inclusions [32,33]. In another recent study, it was reported that the simple addition of extracellular $\alpha \mathrm{S}$ fibrils to primary neurons can also induce the formation of intracellular $\alpha \mathrm{S}$ inclusions [51]. However, in our primary neuronal-glial culture system, the addition of only fibrillar $\alpha \mathrm{S}$ resulted in nuclear pSer129 immunoreactivity with some staining of the processes that did not colocalize with a marker for endogenous $\alpha \mathrm{S}$ (SNL-4), and this staining was still present in cultures from $\alpha \mathrm{S}$ null mice [52] indicating that it is primarily due to crossreactivity. Although it is possible that some of the pSer129 immunostaining seen in neuritic processes of the seeded cultures does represent bonafide inclusion formation, it is imperative that other markers of $\alpha \mathrm{S}$ inclusion pathology show co-localization with the neuritic
pSer129 staining to distinguish inclusion formation from non-specific pSer129 staining. Indeed, the primary reliance on pSer129 immunostaining in both previous neuronal culture studies and in vivo may confound the interpretation of those studies. Overexpression of $\alpha \mathrm{S}$ via rAAV2/1 plus the addition of fibrillar $\alpha S$ were both required for the rapid and efficient formation of $\alpha S$ pathology in our mixed primary neuronal-glial cultures. These aggregates are composed of endogenous $\alpha \mathrm{S}$, and share the biochemical properties of LBs and (Lewy neurites) LNs of being Ser129 hyperphosphorylated, ubiquitinated, Thioflavin-S positive, and Triton X-100 insoluble. They occur in both neurons and astrocytes in a high percentage of both cell types. Although LB and LN pathology in brain tissue samples from PD patients 


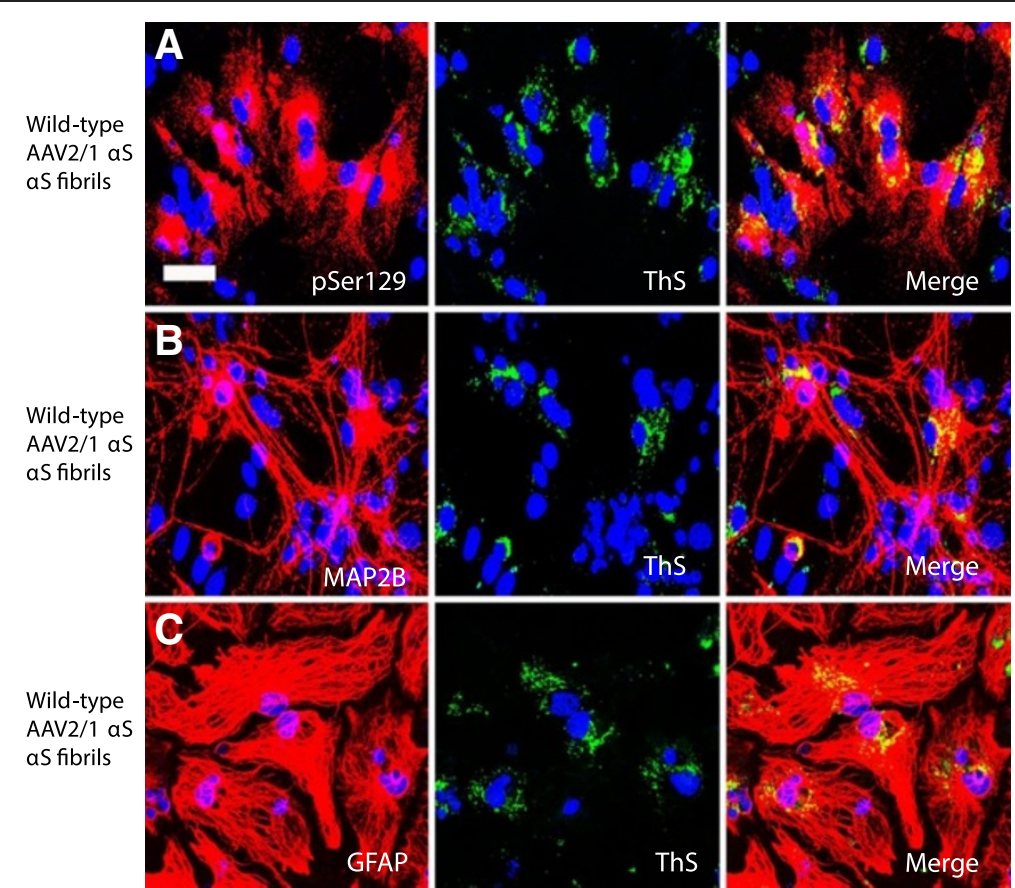

Figure $\mathbf{6}$ aS inclusions induced in mixed neuronal-glial cultures contain Thioflavin- S positive structures. (A) In cultures treated with rAAV2/1 human wild-type aS and human wild-type aS fibrils, pSer129 (red) hyperphosphorylated aS inclusions were also ThS positive (green). This ThS staining profile (green) co-localizes with the neuronal marker MAP2B (red, B) and the astrocyte marker GFAP (red, C). Cultures were counter stained with DAPI (blue). Bar scale $=50 \mu \mathrm{m}$.

is predominantly seen in neurons, $\alpha S$ inclusions can occasionally also be within astrocytes along with a massive astrogliosis surrounding dying neurons in the SNpc of PD patients [53]. Using a mixed culture model where pathology is seen in both cell types allows for further study of the interplay that may be occurring during the pathogenesis of PD. Although subtle differences in experimental paradigms may well-explain the differences between our study and the Volpicelli-Daley et al. study where seeded inclusion formation was reported in
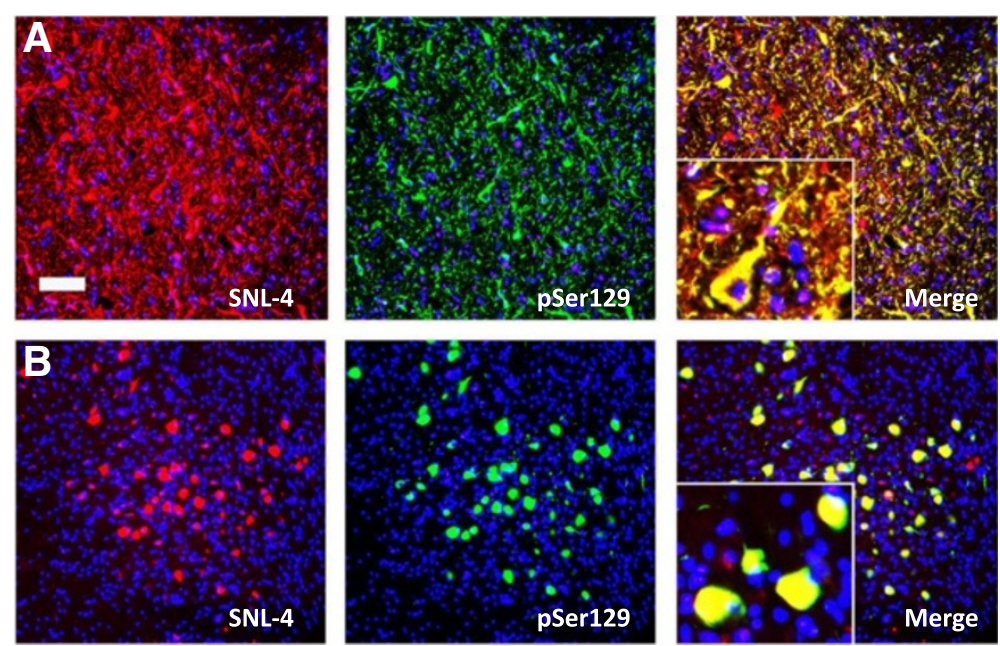

Figure 7 Distinct morphological properties of aS inclusions in M83 (A53T) and M47 (E46K) human aS transgenic mice. (A) Inclusions in M83 transgenic mice stained with aS antibody SNL-4 (red) or pSer129 (green) show a "flame-like" morphology. (B) Inclusions in M47 transgenic mice stained with aS antibody SNL-4 (red) or pSer129 (green) show a "round-like" compact morphology. Sections were counter stained with DAPI. Bar scale $=25 \mu \mathrm{m}$. 

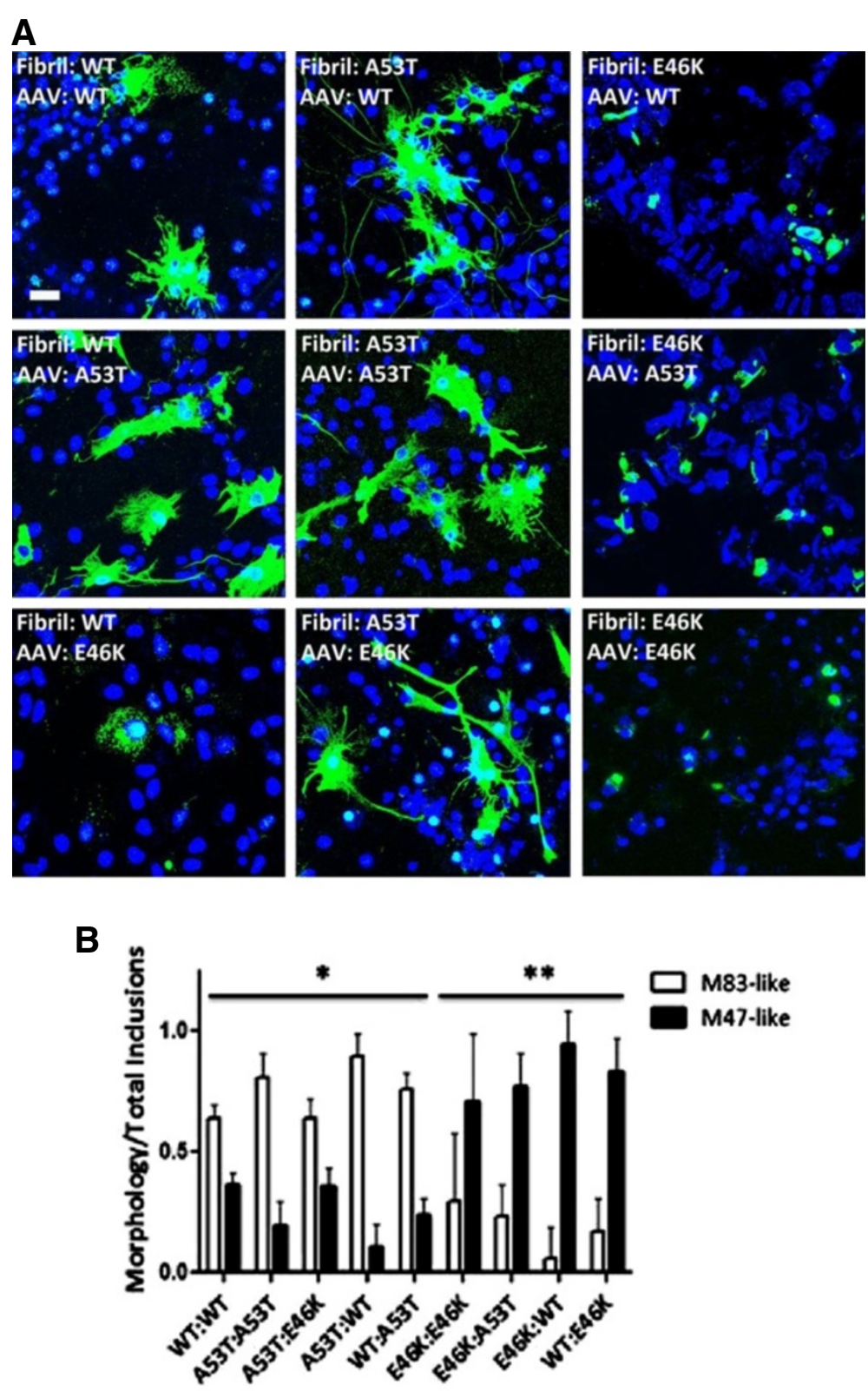

Fibril:AAV Seeding Combinations

Figure 8 aS mutant specific and dominant morphological induction of aS aggregates. (A) Immunofluorescence analysis of morphological differences in aS aggregates is predominantly determined by the type of extracellular aS fibril challenge. Cultures were transduced with rAAV2/1 expressing wild-type, A53T, or E46K aS as indicated in each respective panel and described in Materials and Methods. Cultures were then treated with preformed fibrils comprised of wild-type, A53T, or E46K aS, as indicated in each respective panel. At one day post-seeding (and four days post-seeding for wild-type-wild-type), cultures were fixed and stained with pSer129 antibody (green) to assess for differences in morphology. Cells were counterstained with DAPI (blue). Bar scale $=25 \mu \mathrm{m}$. (B) Quantification of morphological differences for aS aggregates reveals statistical differences in inclusion morphology among seeding combinations. One-way ANOVA with Bonferroni correction for comparison of all groups to each other for flame-like M83 pathology reveals significant differences in inclusion morphology between all A53T fibrillar aS-seeded and E46K fibrillar aS-seeded $\left(^{* *}\right)$ cultures, but not with WT and A53T combinations $\left(^{*}\right)$. Wild-type-wild-type combination $\left(^{*}\right)$ was more likely to result in M83-like inclusion morphology; however, when wild-type fibrils were used to seed either intracellularly expressed mutant proteins, the mutant protein predominantly determined inclusion morphology further indicating the dominant effect of the mutant proteins. $p<0.01 ; n=6$ fields/seeding combination. Values are means \pm SD. 

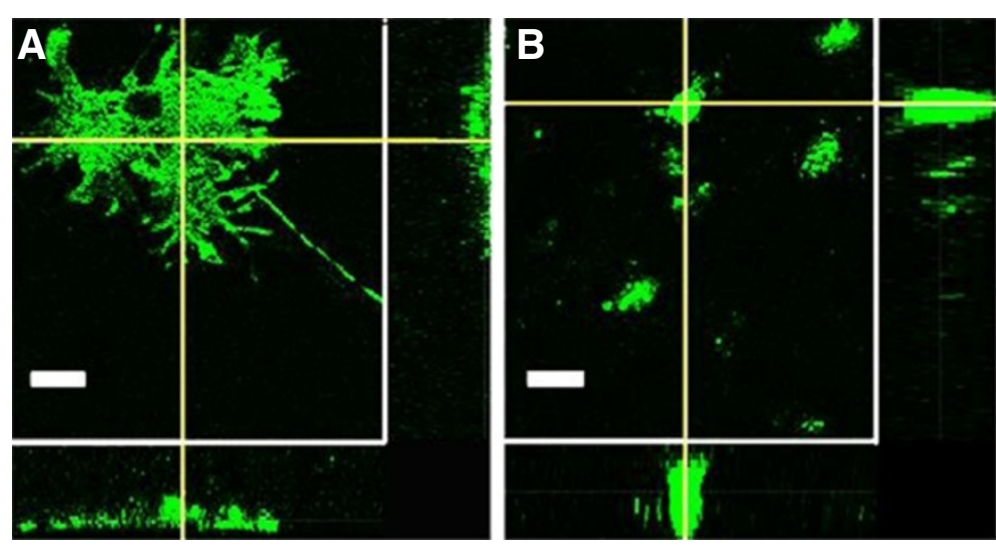

Figure 9 Three-dimensional differences in morphology of aS inclusions. Confocal Z slice analysis midway through the pSer129+aS

aggregates (green) show that (A) M83-like inclusions derived from rAAV2/1-mediated overexpression of human A53T aS and addition of A53T-derived human aS fibrils have a diffuse distribution throughout the cell body. In contrast, (B) M47-like inclusions derived from rAA2/1-mediated overexpression of human E46K aS and addition of E46K-derived human aS fibrils show rounded, punctate staining. Bar scale $=10 \mu \mathrm{m}$.

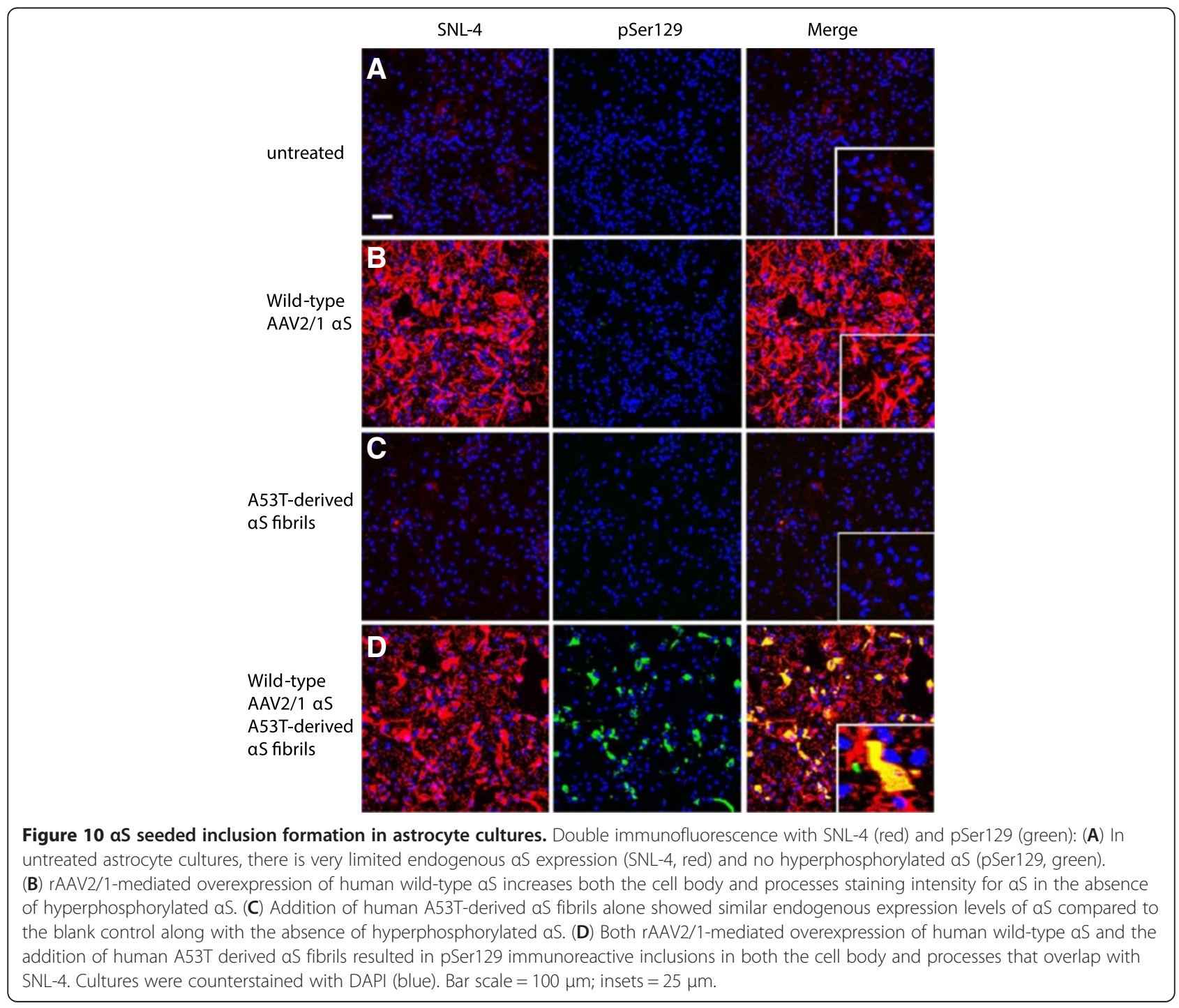




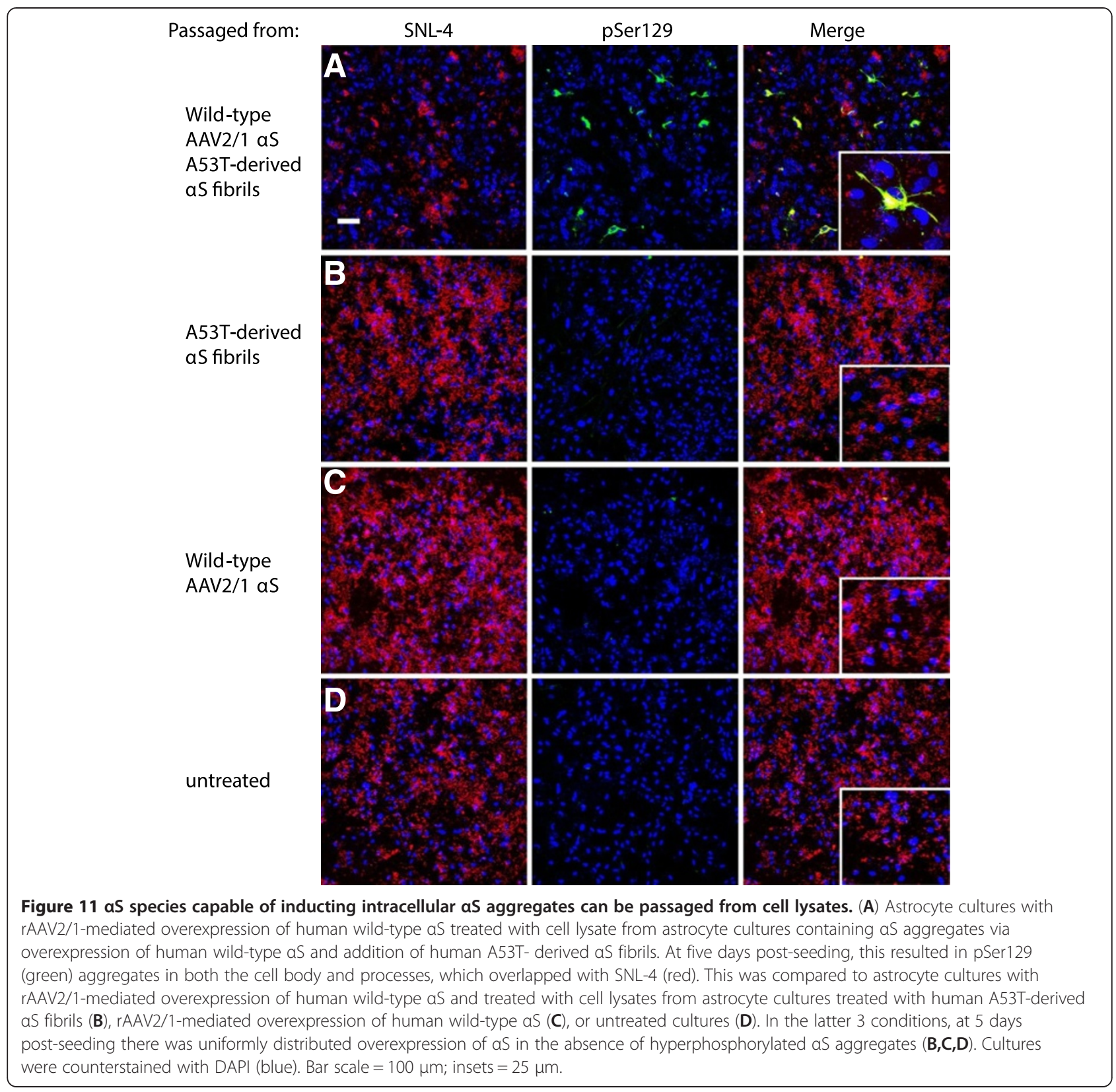

primary neuronal cultures not overexpressing $\alpha \mathrm{S}$ [51], this discrepancy will require further experimental investigation.

Some post-mortem studies of the distribution of $\alpha S$ pathology in the brains of PD patients and the induction of $\alpha \mathrm{S}$ pathology in transplanted neurons in the brains of some PD patients have suggested that $\alpha \mathrm{S}$ pathology may spread from peripheral nerves to the CNS and from the CNS onto grafted neurons [22-26], but different concepts have been proposed to explain the mechanism of pathology propagation. These have included: chronic generalized neuroinflammation, which may promote the up regulation and subsequent aggregation of $\alpha S$; oxidative stress triggered by chronic excitotoxicity, which causes post-translational modifications of $\alpha \mathrm{S}$, such as nitration, that makes the protein more aggregate prone; loss of homeostasis from chronic cellular stress, which may lead to the failure of molecular chaperones and other machinery to effectively control the level of misfolded $\alpha S$; and finally a "prion-like" spread where misfolded $\alpha \mathrm{S}$ is transferred among cells and recruits endogenous $\alpha S$ into pathologic inclusions [54].

Further support for the notion that $\alpha \mathrm{S}$ pathology may spread in the CNS by intercellular release and re-uptake of amyloidogenic $\alpha \mathrm{S}$ are the recent reports showing that intracerebral injection of pre-formed recombinant $\alpha S$ 
fibrils or extracts from sick A53T human $\alpha \mathrm{S}$ transgenic mice (line M83) into younger healthy M83 transgenic mice induces $\alpha \mathrm{S}$ pathology and motor disease [27,55]. Injection of pre-formed recombinant $\alpha \mathrm{S}$ fibrils into wildtype mice was also recently shown to induce brain $\alpha \mathrm{S}$ aggregation that appears to spread from the site of injection [28]. These findings suggest that amyloidogenic $\alpha \mathrm{S}$ species can initiate and perhaps lead to transmission of $\alpha \mathrm{S}$ pathology, but the possibility that the other mechanisms mentioned above may also be involved cannot be excluded.

To further investigate the permissive conformational templating of $\alpha \mathrm{S}$ aggregation, we took advantage of the unique properties of disease-causing mutants A53T and E46K, which also have unique effects on aggregate formation. Both mutations are found in the amino terminus of the protein, proximal to the central hydrophobic stretch (NAC region), which is required for fibrillization of $\alpha \mathrm{S}$ and they accelerate the fibrillization of $\alpha \mathrm{S}$ with the A53T mutation having an increased propensity over the E46K mutation $[18,31,56,57]$. The increased aggregation of these two mutants of $\alpha S$ is due to alterations in the peptide structural order of $\alpha \mathrm{S}$, which influences monomer folding and may make them more susceptible to aggregation $[19,20]$. In addition, in vitro polymerized E46K $\alpha S$ fibrils show district structural and biochemical features compared to wild-type and A53T $\alpha$ S fibrils [17-19,31] and these differences are most likely directly responsible for the different observed morphological conformations of the $\alpha \mathrm{S}$ inclusions in cultured cells and transgenic mice. Our findings that primary cultures expressing wild-type, E46K, or A53T $\alpha \mathrm{S}$ challenged to A53T-derived $\alpha \mathrm{S}$ fibrils mainly resulted in aggregates with a flame-like profile, while similar treatment with E46K-derived $\alpha \mathrm{S}$ fibrils primarily induced the formation of round, compact inclusions demonstrate the conformational templating of $\alpha \mathrm{S}$ aggregation in vivo. It is not clear if the differences in inclusion morphologies result in any significant altered pathophysiological outcomes or if they simply reflect different structure variants. Mice that express E46K or A53T human $\alpha \mathrm{S}$ develop pathological inclusions with these distinct morphological features, but both types of inclusions are associated with similar severe motor phenotype resulting in death $[14,15]$.

These data, along with other evidence that $\alpha \mathrm{S}$ pathology may to be transmissible $[22-24,27,28,58]$, indicates that $\alpha \mathrm{S}$ aggregation may be able to spread intercellularly by conformational templating of amyloid formation akin to a strain-specific prion-like mechanism that has been documented for other prionoid diseases [29,30]. One difference between our model and typical prion strainspecific properties $[29,30]$ is that we studied this phenomenon for $\alpha \mathrm{S}$ using disease-causing mutants, while the same type of process can occur with wild-type prion proteins. Future studies will investigate whether unique post-translational modifications of wild-type $\alpha \mathrm{S}$ can also result in "strain-like" conformational templating. Because both intrinsic perturbations of proteostasis and inflammatory stimuli can induce $\alpha \mathrm{S}$ inclusion formation it is currently challenging to definitively distinguish between true seeding of pathology and other factors that may contribute to inclusion formation in vivo [54]. Based on the morphological seeded templating described here, it should be possible to distinguish between true exogenous seeding and other mechanisms of pathology induction in vivo.

We also show that $\alpha \mathrm{S}$ pathology can be induced in multiple CNS cell types, allowing for studies of how the interplay between these cells may contribute to disease. Because of its efficiency, future studies examining both the prion-like spread and its effect on cellular function can be facilely carried out using this culture model. Further work to provide more support for the "prion-like" spread can be done using this model. One of the characteristics of a "prion-like" spread is that pathology can be continuously passaged from an infected to naïve host and that different prion strains maintain their pathological characteristics [59]. Although we show that $\alpha \mathrm{S}$ aggregation can be passaged from cell lysates derived from astrocytes cultures seeded with A53T $\alpha \mathrm{S}$ fibrils, we are currently expanding our studies to further investigate this phenomenon. These studies will help us to elucidate the mechanisms by which pathology spreads not only in PD but also potentially in other neurodegenerative disorders and help to study a means for therapeutic intervention.

\section{Conclusion}

We report on a novel mixed primary neuronal-glial culture system that can be used as a robust model of $\alpha \mathrm{S}$ aggregate formation. A major advantage of this system is that we can manipulate both the $\alpha \mathrm{S}$ protein expressed and the type of extracellular seeds added. Using this experimental system and disease-causing $\alpha S$ mutants, we show that the addition of extracellular preformed fibrils can induce conformational templating of intracellular aggregates and that the nature of mutant fibrils has a dominant effect on inclusion formation. These studies provide further credence to the notion that $\alpha \mathrm{S}$ pathology may be able to spread via conformational dependent self-templating ("prion-like") mechanisms at least in terms of intercellular transmission and induction of change in protein conformation by direct protein interaction. If such conformational templating occurs in vivo, then distinct inclusion morphology induced by distinct $\alpha \mathrm{S}$ may be one surrogate that can be used to distinguish between seeded templating and other mechanisms of inducing $\alpha \mathrm{S}$ pathology in vivo. 


\section{Materials and methods}

\section{Mixed neuronal-glial primary cultures}

All procedures were performed according to the $\mathrm{NIH}$ Guide for the Care and Use of Experimental Animals and were approved by the University of Florida Institutional Animal Care and Use Committee. SNCA null mice [52] were obtained from The Jackson Laboratory (Bar Harbor, MA). Primary cultures were prepared from P0 C3HBL/6 mouse brains (Harlan Labs). Cerebral cortices were dissected from P0 mouse brains and were dissociated in $2 \mathrm{mg} / \mathrm{mL}$ papain (Worthington) and $50 \mu \mathrm{g} / \mathrm{mL}$ DNAase I (Sigma) in sterile Hank's Balanced Salt Solution (HBSS, Life Technologies) at $37^{\circ} \mathrm{C}$ for 20 minutes. They were then washed three times in sterile HBSS to inactivate the papain and switched to $5 \%$ fetal bovine serum (HyClone) in Neurobasal-A growth media (Gibco), which includes $0.5 \mathrm{mM}$ L-glutamine (Gibco), $0.5 \mathrm{mM}$ GlutaMax (Life Technologies), 0.01\% antibiotic-antimycotic (Gibco), and $0.02 \%$ SM1 supplement (Stemcell). The tissue mixture was then triturated three times using a $5 \mathrm{~mL}$ pipette followed by a Pasteur pipette, and strained through a $70 \mu \mathrm{m}$ cell strainer. The cell mixture was then centrifuged at $200 \mathrm{~g}$ for 3 minutes, and re-suspended in fresh Neurobasal-A media. They were then plated onto poly-D lysine coated chamber slides (Life Technologies) or dishes at around 100,000-200,000 cells $/ \mathrm{cm}^{2}$. Cells were maintained in the Neurobasal-A growth media mentioned above without fetal bovine serum at $37^{\circ} \mathrm{C}$ in a humidified $5 \% \mathrm{CO}_{2}$ chamber.

\section{rAAV2/1 preparation and expression}

rAAV serotype 2/1 expressing human wild-type, A53T or E46K $\alpha \mathrm{S}$ under the control of the CMV early enhancer/chicken $\beta$ actin (CAG) promoter, were generated as described previously [60]. At 5 days in vitro (DIV), each virus was added to cultures at a final concentration of $10^{11}$ genome copies $/ \mathrm{mL}$. We have determined that at $12 \mathrm{DIV}, \sim 40 \%+$ of cells in our cultures are transduced by rAAV2-1.

\section{Preparation of recombinant aS fibrils}

Recombinant, human $\beta$-synuclein and 21-140, wild-type, A53T, E46K, and $\Delta 71-82 \alpha \mathrm{S}$ proteins were expressed and purified as described previously [31,32,34,41]. For amyloid assembly 21-140, wild-type, A53T, and E46K $\alpha \mathrm{S}$ proteins $(5 \mathrm{mg} / \mathrm{mL})$ were incubated in sterile phosphate-buffered saline (PBS; Life Technologies, Carlsbad, CA, USA) at $37^{\circ} \mathrm{C}$ with continuous shaking at $1050 \mathrm{rpm}$ (Thermomixer R, Eppendorf, Westbury, NY, USA) and fibril formation was monitored by turbidity and K114 fluorometry [32]. Fibrils were diluted to $1 \mathrm{mg} / \mathrm{mL}$ in sterile PBS and sonicated for 2 hours, which results in fragmentation into smaller fibrils of varying lengths [32,33]. Cultures were treated with $1 \mu \mathrm{M}$ of fibril mix at $8 \mathrm{DIV}$.

Fibrils pre-labeled with Thioflavin-S (ThS) were only used where indicated. A $1 \mathrm{mg} / \mathrm{mL}$ fibril mix was incubated in $0.05 \%$ ThS for 1 hour then spun at 16,000 $\mathrm{g}$ for 5 minutes, and washed with PBS three to five times and sonicated for 2 hours. Fibril mix was then added to cultures at a final concentration of $1 \mu \mathrm{M}$.

\section{Biochemical cellular fractionation and western blotting analysis}

Samples for biochemical analysis were harvested at 4 days post-seeding. Cultures were washed in PBS and scraped in 1\% Tx-100 TBS (50 mM Tris, $150 \mathrm{mM} \mathrm{NaCl}$, $\mathrm{pH}$ 7.4) with protease and phosphatase inhibitors and placed on ice for $10 \mathrm{~min}$. Lysates were then centrifuged at $100,000 \mathrm{~g}$ for $20 \mathrm{~min}$ at $4^{\circ} \mathrm{C}$. Supernatants were removed (Triton-soluble fraction), and the pellet was washed with the TBS buffer and re-centrifuged. The remaining pellet was then resuspended in $2 \%$ SDS, sonicated and heated to $100^{\circ} \mathrm{C}$ for $10 \mathrm{~min}$ (Triton-insoluble fraction). $2 \%$ SDS was added to the Triton-soluble fraction that was heated to $100^{\circ} \mathrm{C}$. Equal amounts of protein were resolved by SDS-PAGE on $15 \%$ polyacrylamide gels, followed by electrophoretic transfer onto nitrocellulose membranes. Membranes were blocked in TBS with $5 \%$ dry milk, and incubated overnight with Syn211, a mouse monoclonal antibody specific for amino acids 121-125 in human $\alpha S$ [61], in TBS/5\% dry milk, or pSer129, a mouse monoclonal antibody specific for $\alpha S$ phosphorylated at Ser129 [35], in TBS/5\% bovine serum albumin (BSA). A total anti-actin antibody (clone C4) (Millipore, Billerica, MA) was used as a loading control. Each incubation was followed by goat anti-mouse conjugated horseradish peroxidase (HRP) (Amersham Biosciences, Piscataway, NJ). Protein bands were detected using chemiluminescent reagent (NEN, Boston, MA) and a FluorChem E and M Imager (Proteinsimple, San Jose, California).

\section{Immunofluorescence microscopy analysis}

Samples for immunofluorescence analysis were taken at 4 days post-seeding (and at 1 day post-seeding where indicated). For double immunofluorescence analysis, cells were fixed with $4 \%$ paraformaldehyde/PBS. Following PBS washes, cells were blocked with $5 \%$ goat serum/ PBS/0.3\% Triton X-100 for 1 hour. Cultures were incubated in primary antibodies: pSer129 (1:500) and SNL-4 (1:500), a rabbit polyclonal antibody raised against amino acid sequence $2-12$ of human $\alpha \mathrm{S}$, but that also reacts with murine $\alpha S$ [61]. Other primary antibodies include rabbit polyclonal anti-MAP2B (1:100), a neuronal marker (Millipore); rabbit polyclonal anti-GFAP (1:1000), an astrocyte marker (Dako); and rabbit polyclonal anti-ubiquitin 
(1:1000) (Abcam). This was followed by incubation with Alexa-fluor 488 and 594 conjugated secondary antibodies (1:1000) (Invitrogen). Nuclei were counterstained with 4',6-diamidino-2-phenylindole (DAPI; Invitrogen), and coverslips were mounted using Fluoromount-G (Southern Biotech, Birmingham, AL). Thioflavin-S (Sigma-Aldrich) immunostaining was performed after secondary antibody incubation at a concentration of $0.05 \%$ followed by three washes in $70 \%$ ethanol and three washes in water. Images were captured on a Leica TCS SP2 AOBS Spectral Confocal Scanner mounted on a Leica DM IRE2 inverted fluorescent microscope. All images were captured with either $20 \times$ or $63 \times$ water immersion objectives as projection images from a Z-stack of $<1.0 \mu \mathrm{m}$ per plane.

\section{Astrocyte cultures}

All procedures were performed according to the NIH Guide for the Care and Use of Experimental Animals and were approved by the University of Florida Institutional Animal Care and Use Committee. Astrocyte cultures were prepared from P2 C3HBL/6 mouse brains (Harlan Labs). Cerebral cortices were dissected from P2 mouse brains and were dissociated in $2 \mathrm{mg} / \mathrm{mL}$ papain (Worthington) and $50 \mathrm{mg} / \mathrm{mL}$ DNAase I (Sigma) in sterile Hank's Balanced Salt Solution (HBSS, Life Technologies) at $37^{\circ} \mathrm{C}$ for 20 minutes. They were then washed three times in sterile HBSS to inactivate the papain and switched to Dulbecco's Modified Eagle Medium (Life Technologies) with $10 \%$ fetal bovine serum (Life Technologies) and $100 \mathrm{U} / \mathrm{mL}$ Penicillin and $100 \mu \mathrm{g} / \mathrm{mL}$ Streptomycin (Life Technologies). The tissue mixture was then triturated three times using a $5 \mathrm{~mL}$ pipette followed by a Pasteur pipette and strained through a 70 $\mu \mathrm{m}$ cell strainer. The cell mixture was then centrifuged at $200 \mathrm{~g}$ for 3 minutes, and re-suspended in fresh DMEM media. They were then plated in chamber slides, $10 \mathrm{~cm}$ culture dishes, or T-75 flasks at 75,000 to 200,000 cells $/ \mathrm{cm}^{2}$. Cells were maintained in the DMEM media mentioned above at $37^{\circ} \mathrm{C}$ in a humidified $5 \% \mathrm{CO}_{2}$ chamber. After two days, flasks were shaken for 30 seconds and supplied with fresh media. Upon reaching confluency, flasks were split using TrypLE Express (Life Technologies) for two generations per original culture.

\section{Cell lysate passaging in astrocyte cultures}

Since induction of $\alpha \mathrm{S}$ aggregates was seen in both neurons and astrocytes in mixed cultures, astrocyte cultures were used because they can be split which facilitated the passaging experiments. The first generation astrocyte cultures were split into $10 \mathrm{~cm}$ culture dishes at 75,000 cells $/ \mathrm{cm}^{2}$. rAAV 2/1 expressing human wild-type $\alpha \mathrm{S}$, as described above, was added at 3 days following plating at a final concentration of $10^{11}$ genome copies $/ \mathrm{mL}$. At 5 days following plating, the media was changed and cultures were treated with $1 \mu \mathrm{M} \alpha \mathrm{S}$ fibril mix for 5 days. Cultures were then washed three times in PBS and incubated in $0.25 \%$ Trypsin-EDTA (Life Technologies) for 10 minutes to inactivate residual extracellular $\alpha \mathrm{S}$ fibrils. Cells were then collected in DMEM and spun at $200 \mathrm{~g}$ for 5 minutes. Pellets were rinsed with PBS and then frozen.

The second generation astrocyte cultures were again split and were transduced with rAAV 2/1 expressing human wild-type $\alpha S$, as mentioned above, for two days. Then the cell pellets from the first generation cultures were thawed, re-suspended in $1 \mathrm{~mL}$ PBS, and lysated by sheer force with a $27 \mathrm{~g}$ needle. $100 \mu \mathrm{L}$ of this lysate was then added to the second generation astrocyte cultures for 5 days.

\section{Quantitative analysis}

Observations of morphological differences in $\alpha \mathrm{S}$ were made by observer blinded, random field counting. Images were captured with an Olympus BX51 fluorescence microscope mounted with a DP71 digital camera (Olympus, Center Valley, PA) using 10× magnification and imaged were enlarged with Photoshop software and using a grid to allow for total field counting. For each seeding combination, 6 fields were counted. Criteria for inclusion morphology were set according to that seen in the M83 and M47 mouse models (see Results Figure 7). Briefly, either M83-like filling the somatodendritic compartment or M47-like with compact and rounded perinuclear inclusions. Results were expressed as the mean ratio of cells showing either type of morphology to the total number of inclusions per field \pm SD. Comparisons for significance were made using one-way ANOVA with Bonferroni's post-hoc test in GraphPad Prism software (San Diego, CA).

\section{Abbreviations}

aS: a-Synuclein; LB: Lewy body; LN: Lewy neurite; PD: Parkinson's disease; rAAV: recombinant adeno-associated virus.

\section{Competing interests}

The authors declare that they have no competing interests.

\section{Authors' contributions}

ANS designed the study, performed culture experiments, analyzed the data, and drafted the manuscript. MAT performed culture experiments, and analyzed the data. CCD participated in the design of the study and performed culture experiments. PEC constructed the rAAV2/1 used and performed culture experiments. AMR helped to construct the rAAV2/1 used and performed culture experiments. JL participated in the design and coordination of the study. BIG and TEG participated in the design and coordination of the study, analyzed the data, and helped to draft the manuscript. All authors read and approved the final manuscript.

\section{Acknowledgements}

This work was supported by an Ellison Medical Foundation Senior Scholar Award to TEG and funding from the University of Florida.

Received: 9 February 2013 Accepted: 15 May 2013

Published: 28 May 2013 


\section{References}

1. Dorsey ER, Constantinescu R, Thompson JP, Biglan KM, Holloway RG, Kieburtz K, Marshall FJ, Ravina BM, Schifitto G, Siderowf A, Tanner CM: Projected number of people with Parkinson disease in the most populous nations, 2005 through 2030. Neurology 2007, 68(5):384-386.

2. Spillantini MG, Schmidt ML, LEE VM, Trojanowski JQ, Jakes R, Goedert M: Alpha-synuclein in Lewy bodies. Nature 1997, 388(6645):839-840.

3. Goedert M: Alpha-synuclein and neurodegenerative diseases. Nat Rev Neurosci 2001, 2(7):492-501.

4. Polymeropoulos MH, Lavedan C, Leroy E, Ide SE, Dehejia A, Dutra A, Pike B, Root H, Rubenstein J, Boyer R, Stenroos ES, Chandrasekharappa S, Athanassiadou A, Papapetropoulos T, Johnson WG, Lazzarini AM, Duvoisin RC, Di lorio G, Golbe LI, Nussbaum RL: Mutation in the alpha-synuclein gene identified in families with Parkinson's disease. Science 1997, 276(5321):2045-2047.

5. Zarranz JJ, Alegre J, Gómez-Esteban JC, Lezcano E, Ros R, Ampuero I, Vidal L, Hoenicka J, Rodriguez O, Atarés B, Llorens V, Gomez Tortosa E, del Ser T, Muñoz DG, de Yebenes JG: The new mutation, E46K, of alpha-synuclein causes Parkinson and Lewy body dementia. Ann Neurol 2004, 55(2):164-173.

6. Singleton $A B$, Farrer $M$, Johnson J, Singleton $A$, Hague S, Kachergus J, Hulihan M, Peuralinna T, Dutra A, Nussbaum R, Lincoln S, Crawley A, Hanson M, Maraganore D, Adler C, Cookson MR, Muenter M, Baptista M, Miller D, Blancato J, Hardy J, Gwinn-Hardy K: alpha-Synuclein locus triplication causes Parkinson's disease. Science 2003, 302(5646):841.

7. Kruger R, Kuhn W, Muller T, Woitalla D, Graeber M, Kosel S, Przuntek H, Epplen JT, Schols L, Riess O: Ala30Pro mutation in the gene encoding alpha-synuclein in Parkinson's disease. Nat Genet 1998, 18(2):106-108.

8. Farrer M, Kachergus J, Forno L, Lincoln S, Wang DS, Hulihan M, Maraganore D, Gwinn-Hardy K, Wszolek Z, Dickson D, Langston JW: Comparison of kindreds with parkinsonism and alpha-synuclein genomic multiplications. Ann Neurol 2004, 55(2):174-179.

9. Chartier-Harlin MC, Kachergus J, Roumier C, Mouroux V, Douay X, Lincoln S, Levecque C, Larvor L, Andrieux J, Hulihan M, Waucquier N, Defebvre L, Amouyel P, Farrer M, Destée A: Alpha-synuclein locus duplication as a cause of familial Parkinson's disease. Lancet 2004, 364(9440):1 167-1169.

10. Lesage S, Letournel F, Bousset L, Honoré A, Rozas N, Pieri L, Madiona K, Dürr A, Melki R, Verny C, Brice A: G51D alpha-synuclein mutation causes a novel parkinsonian-pyramidal syndrome. Ann Neurol 2013 (in press).

11. Appel-Cresswell S, Vilarino-Guell C, Encarnacion M, Sherman H, Yu I, Shah B, Weir D, Thompson C, Szu-Tu C, Trinh J, Aasly JO, Rajput A, Rajput AH, Jon Stoessl A, Farrer MJ: Alpha-synuclein p.H50Q, a novel pathogenic mutation for Parkinson's disease. Mov Disord 2013 (in press).

12. Proukakis C, Dudzik CG, Brier T, Mackay DS, Cooper JM, Millhauser GL, Houlden $\mathrm{H}$, Schapira AH: A novel alpha-synuclein missense mutation in Parkinson disease. Neurology 2013, 80(11):1062-1064.

13. Kiely AP, Asi YT, Kara E, Limousin P, Ling H, Lewis P, Proukakis C, Quinn N, Lees AJ, Hardy J, Revesz T, Houlden H, Holton JL: alpha-Synucleinopathy associated with G51D SNCA mutation: a link between Parkinson's disease and multiple system atrophy? Acta Neuropathol 2013, 125(5):753-769.

14. Emmer KL, Waxman EA, Covy JP, Giasson BI: E46K human alpha-synuclein transgenic mice develop Lewy-like and tau pathology associated with age-dependent, detrimental motor impairment. J Biol Chem 2011, 286(40):35104-35118.

15. Giasson BI, Duda JE, Quinn SM, Zhang B, Trojanowski JQ, Lee VM: Neuronal alpha-synucleinopathy with severe movement disorder in mice expressing A53T human alpha-synuclein. Neuron 2002, 34(4):521-533.

16. Duda JE, Giasson BI, Mabon ME, Miller DC, Golbe LI, Lee VM, Trojanowski JQ: Concurrence of alpha-synuclein and tau brain pathology in the Contursi kindred. Acta Neuropathol 2002, 104(1):7-11.

17. Ono K, Ikeda T, Takasaki J, Yamada M: Familial Parkinson disease mutations influence alpha-synuclein assembly. Neurobiol Dis 2011, 43(3):715-724.

18. Giasson BI, Uryu K, Trojanowski JQ, Lee VM: Mutant and wild type human alpha-synucleins assemble into elongated filaments with distinct morphologies in vitro. J Biol Chem 1999, 274(12):7619-7622.

19. Comellas G, Lemkau LR, Nieuwkoop AJ, Kloepper KD, Ladror DT, Ebisu R, Woods WS, Lipton AS, George JM, Rienstra CM: Structured regions of alpha-synuclein fibrils include the early-onset Parkinson's disease mutation sites. J Mol Biol 2011, 411(4):881-895.

20. Rospigliosi CC, McClendon S, Schmid AW, Ramlall TF, Barre P, Lashuel HA, Eliezer D: E46K Parkinson's-linked mutation enhances C-terminal-to-Nterminal contacts in alpha-synuclein. J Mol Biol 2009, 388(5):1022-1032.
21. Brucale M, Sandal M, Di Maio S, Rampioni A, Tessari I, Tosatto L, Bisaglia M, Bubacco L, Samori B: Pathogenic mutations shift the equilibria of alphasynuclein single molecules towards structured conformers. ChemBioChem 2009, 10(1):176-183.

22. Kordower JH, Chu Y, Hauser RA, Freeman TB, Olanow CW: Lewy body-like pathology in long-term embryonic nigral transplants in Parkinson's disease. Nat Med 2008, 14(5):504-506.

23. Li JY, Englund E, Holton JL, Soulet D, Hagell P, Lees AJ, Lashley T, Quinn NP, Rehncrona S, Björklund A, Widner H, Revesz T, Lindvall O, Brundin P: Lewy bodies in grafted neurons in subjects with Parkinson's disease suggest host-to-graft disease propagation. Nat Med 2008, 14(5):501-503.

24. Mendez I, Viñuela A, Astradsson A, Mukhida K, Hallett P, Robertson H, Tierney T, Holness R, Dagher A, Trojanowski JQ, Isacson O: Dopamine neurons implanted into people with Parkinson's disease survive without pathology for 14 years. Nat Med 2008, 14(5):507-509.

25. Braak H, Del Tredici K, Rüb U, de Vos RA, Jansen Steur EN, Braak E: Staging of brain pathology related to sporadic Parkinson's disease. Neurobiol Aging 2003, 24(2):197-211.

26. Braak H, Rub U, Gai WP, Del Tredici K: Idiopathic Parkinson's disease: possible routes by which vulnerable neuronal types may be subject to neuroinvasion by an unknown pathogen. J Neural Transm 2003, 110(5):517-536.

27. Luk KC, Kehm VM, Zhang B, O'Brien P, Trojanowski JQ, Lee VM: Intracerebral inoculation of pathological alpha-synuclein initiates a rapidly progressive neurodegenerative alpha-synucleinopathy in mice. J Exp Med 2012, 209(5):975-986.

28. Luk KC, Luk KC, Kehm V, Carroll J, Zhang B, O'Brien, Trojanowski JQ, Lee VM: Pathological alpha-synuclein transmission initiates Parkinson-like neurodegeneration in nontransgenic mice. Science 2012, 338(6109):949-953.

29. Eisenberg D, Jucker M: The amyloid state of proteins in human diseases. Cell 2012, 148(6):1188-1203.

30. Aguzzi A, Heikenwalder M, Polymenidou M: Insights into prion strains and neurotoxicity. Nat Rev Mol Cell Biol 2007, 8(7):552-561.

31. Greenbaum EA, Graves CL, Mishizen-Eberz AJ, Lupoli MA, Lynch DR, Englander SW, Axelsen PH, Giasson BI: The E46K mutation in alphasynuclein increases amyloid fibril formation. J Biol Chem 2005, 280(9):7800-7807.

32. Waxman EA, Giasson Bl: A novel, high-efficiency cellular model of fibrillar alpha-synuclein inclusions and the examination of mutations that inhibit amyloid formation. J Neurochem 2010, 113(2):374-388.

33. Luk KC, Song C, O'Brien P, Stiever A, Branch JR, Brunden KR, Trojanowski JQ, Lee VM: Exogenous alpha-synuclein fibrils seed the formation of Lewy body-like intracellular inclusions in cultured cells. Proc Natl Acad Sci U S A 2009, 106(47):20051-20056.

34. Waxman EA, Giasson BI: Induction of intracellular tau aggregation is promoted by alpha-synuclein seeds and provides novel insights into the hyperphosphorylation of tau. J Neurosci 2011, 31(21):7604-7618.

35. Waxman EA, Giasson BI: Specificity and regulation of casein kinasemediated phosphorylation of alpha-synuclein. J Neuropathol Exp Neurol 2008, 67(5):402-416.

36. Fujiwara H, Hasegawa M, Dohmae N, Kawashima A, Masliah E, Goldberg MS, Shen J, Takio K, Iwatsubo T: alpha-Synuclein is phosphorylated in synucleinopathy lesions. Nat Cell Biol 2002, 4(2):160-164.

37. Anderson JP, Walker DE, Goldstein JM, de Laat R, Banducci K, Caccavello RJ, Barbour R, Huang J, Kling K, Lee M, Diep L, Keim PS, Shen X, Chataway T, Schlossmacher MG, Seubert P, Schenk D, Sinha S, Gai WP, Chilcote TJ: Phosphorylation of Ser-129 is the dominant pathological modification of alpha-synuclein in familial and sporadic Lewy body disease. J Biol Chem 2006, 281(40):29739-29752.

38. Waxman EA, Giasson Bl: Characterization of kinases involved in the phosphorylation of aggregated alpha-synuclein. J Neurosci Res 2011 89(2):231-247

39. Withers GS, George JM, Banker GA, Clayton DF: Delayed localization of synelfin (synuclein, NACP) to presynaptic terminals in cultured rat hippocampal neurons. Brain Res Dev Brain Res 1997, 99(1):87-94.

40. Murphy DD, Rueter SM, Trojanowski JQ, Lee VM: Synucleins are developmentally expressed, and alpha-synuclein regulates the size of the presynaptic vesicular pool in primary hippocampal neurons. J Neurosci 2000, 20(9):3214-3220.

41. Giasson BI, Murray IV, Trojanowski JQ, Lee VM: A hydrophobic stretch of 12 amino acid residues in the middle of alpha-synuclein is essential for filament assembly. J Biol Chem 2001, 276(4):2380-2386. 
42. George JM, Jin H, Woods WS, Clayton DF: Characterization of a novel protein regulated during the critical period for song learning in the zebra finch. Neuron 1995, 15(2):361-372.

43. Jakes R, Spillantini MG, Goedert M: Identification of two distinct synucleins from human brain. FEBS Lett 1994, 345(1):27-32.

44. Iwai A, Masliah E, Yoshimoto M, Ge N, Flanagan L, de Silva HA, Kittel A Saitoh T: The precursor protein of non-A beta component of Alzheimer's disease amyloid is a presynaptic protein of the central nervous system. Neuron 1995, 14(2):467-475.

45. Waxman EA, Giasson Bl: Molecular mechanisms of alpha-synuclein neurodegeneration. Biochim Biophys Acta 2009, 1792(7):616-624.

46. Cookson MR: The biochemistry of Parkinson's disease. Annu Rev Biochem 2005, 74:29-52.

47. Norris EH, Giasson Bl, Lee VM: Alpha-synuclein: normal function and role in neurodegenerative diseases. Curr Top Dev Biol 2004, 60:17-54.

48. Goldberg MS, Lansbury PT Jr: Is there a cause-and-effect relationship between alpha-synuclein fibrillization and Parkinson's disease? Nat Cell Biol 2000, 2(7):E115-E119.

49. Uversky VN: Neuropathology, biochemistry, and biophysics of alphasynuclein aggregation. J Neurochem 2007, 103(1):17-37.

50. Wood SJ, Wypych J, Steavenson S, Louis JC, Citron M, Biere AL: alphasynuclein fibrillogenesis is nucleation-dependent: implications for the pathogenesis of Parkinson's disease. J Biol Chem 1999, 274(28):19509-19512.

51. Volpicelli-Daley LA, Luk KC, Patel TP, Tanik SA, Riddle DM, Stiever A, Meaney DF, Trojanowski JQ, Lee VM: Exogenous alpha-synuclein fibrils induce Lewy body pathology leading to synaptic dysfunction and neuron death. Neuron 2011, 72(1):57-71.

52. Abeliovich A, Schmitz Y, Fariñas I, Choi-Lundberg D, Ho WH, Castillo PE, Shinsky N, Verdugo JM, Armanini M, Ryan A, Hynes M, Phillips H, Sulzer D, Rosenthal A: Mice lacking alpha-synuclein display functional deficits in the nigrostriatal dopamine system. Neuron 2000, 25(1):239-252.

53. Halliday GM, Stevens $\mathrm{CH}$ : Glia: initiators and progressors of pathology in Parkinson's disease. Mov Disord 2011, 26(1):6-17.

54. Brundin P, Li JY, Holton JL, Lindvall O, Revesz T: Research in motion: the enigma of Parkinson's disease pathology spread. Nat Rev Neurosci 2008, 9(10):741-745.

55. Mougenot AL, Nicot S, Bencsik A, Morignat E, Verchere J, Lakhdar L, Legastelois S, Baron T: Prion-like acceleration of a synucleinopathy in a transgenic mouse model. Neurobiol Aging 2012, 33(9):2225-2228.

56. Conway KA, Harper JD, Lansbury PT: Accelerated in vitro fibril formation by a mutant alpha-synuclein linked to early-onset Parkinson disease. Nat Med 1998, 4(11):1318-1320.

57. Narhi L, Wood SJ, Steavenson S, Jiang Y, Wu GM, Anafi D, Kaufman SA, Martin F, Sitney K, Denis P, Louis JC, Wypych J, Biere AL, Citron M: Both familial Parkinson's disease mutations accelerate alpha-synuclein aggregation. J Biol Chem 1999, 274(14):9843-9846.

58. Lee HJ, Suk JE, Patrick C, Bae EJ, Cho JH, Rho S, Hwang D, Masliah E, Lee SJ: Direct transfer of alpha-synuclein from neuron to astroglia causes inflammatory responses in synucleinopathies. J Biol Chem 2010, 285(12): 9262-9272.

59. Collinge J, Clarke AR: A general model of prion strains and their pathogenicity. Science 2007, 318(5852):930-936.

60. Kim J, Miller VM, Levites Y, West KJ, Zwizinski CW, Moore BD, Troendle FJ, Bann M, Verbeeck C, Price RW, Smithson L, Sonoda L, Wagg K, Rangachari V, Zou F, Younkin SG, Graff-Radford N, Dickson D, Rosenberry T, Golde TE: BRI2 (ITM2b) inhibits abeta deposition in vivo. J Neurosci 2008, 28(23):6030-6036.

61. Giasson BI, Jakes R, Goedert M, Duda JE, Leight S, Trojanowski JQ, Lee VM: A panel of epitope-specific antibodies detects protein domains distributed throughout human alpha-synuclein in Lewy bodies of Parkinson's disease. J Neurosci Res 2000, 59(4):528-533.

doi:10.1186/1750-1326-8-17

Cite this article as: Sacino et al:: Conformational templating of asynuclein aggregates in neuronal-glial cultures. Molecular Neurodegeneration 2013 8:17.

\section{Submit your next manuscript to BioMed Central and take full advantage of:}

- Convenient online submission

- Thorough peer review

- No space constraints or color figure charges

- Immediate publication on acceptance

- Inclusion in PubMed, CAS, Scopus and Google Scholar

- Research which is freely available for redistribution

Submit your manuscript at www.biomedcentral.com/submit 